\title{
24 Cognitive development and classroom interaction: a theoretical foundation for teaching and learning
}

\author{
Mundher Adhami, David C. Johnson and Michael Shayer \\ School of Education, King's College \\ University of London, United Kingdom
}

\begin{abstract}
The Cognitive Acceleration in Mathematics Education (CAME) project aims to contribute to teachers' professional development by basing practice on research and theory. Three major sources are drawn upon: Research on levels of achievement in mathematical topics; Piagetian and neo-Piagetian theories on levels of thinking (formal reasoning); and Vygotskian psychology and social constructivism. These sources have been integrated to provide a theoretical foundation for teacher intervention and pupil-pupil interaction aimed at increasing intellectual development. Exploratory IT environments provide particularly suitable contexts for illuminating the approach. Findings indicate the potential for substantial long-term impact on pupils' achievements.
\end{abstract}

\section{Keywords}

Classroom practice, cognition, collaborative learning, (social) constructivism.

\section{BACKGROUND DEVELOPMENTS, 1977-1997}

A concern for theory and implications of developments in psychology to underpin classroom practice has been present in each of the earlier IFIP WG 3.1 working conferences on informatics and school mathematics in Bulgaria: 1977 in Varna, and 1987 in Sofia. In Varna, Kilpatrick (1978), in addressing the importance of theory and new developments indicated that:

" a new wave of cognitive theory was building ... reforms proposed (on the new theories) were justified on the basis of principles derived ... but who can say what tomorrow may bring?" (p.93). 
In Sofia, Jensen and Nissen (1987) put forward a model for school learning with a focus on teachers and the interactions of teaching and learning processes in the classroom:

"Our focus has been to try to stipulate categories for description of the individual potential for acquisition, which - in the pedagogical progression - interacts with the teacher's expression of knowledge" ( $p$ 73).

The concern for the learner has evolved and grown, and as such represented one of the main themes in an IFIP conference, in Gmunden, Austria in 1993. While this conference did not focus on school subjects, mathematics provided one of the contexts for the paper by De Corte (1993) in which he went beyond the individual, pupil and/or teacher, to a consideration of the broader learning environment and issues which needed to be addressed:

“... the trend for future inquiry and development at the intersection of artificial intelligence, cognitive science, educational technology, and learning and instruction ... we are only at the beginning of what may become a new era in educational computing ... the further elaboration and testing of research-based principles for the design of powerful computersupported learning environments ... (including a consideration of, e.g.) the balance between discovery and exploration, on the one hand, and guidance and mediation, on the other, that can account for the power and efficacy of these environments" (p 45).

It is noted here that the extracts above illustrate an interesting trend in terms of how one might now consider implications of research and theory for the teaching and learning of school mathematics. The shift from a focus on the child's mental structures, with minimal reference to teaching and/or the classroom environment, to more attention given to the individual, child and teacher, in the school context and ultimately the learning environment, including aspects of mediation, reflect both what we have learned and synthesised from research along with an acknowledgement of the complexity of the phenomena we would hope to analyse and inform, namely classroom practice. However, this base, including both 'old' and 'new' theoretical perspectives, i.e., it is not merely a case that new theories provide the answers, but rather we would suggest that there is much to be gained through an integration of both the 'new' and 'old', now places us in a unique position to address the issue of 'the utilisation of research and theory to underpin an approach to classroom practice for school mathematics'. 
Adhami, Johnson \& Shayer: Cognitive development and classroom interaction 207

\section{PIAGET, VYGOTSKY AND SOCIAL CONSTRUCTIVISM}

\section{Piaget}

Piagetian research remained foremost in its contribution to our understanding of cognitive development of children. Many aspects of the Piagetian theory and research conducted in clinical trials over a period of 30 years have been questioned. Apart from the confusing terminology, that created and still creates many problems of communication amongst researchers and teachers, there have been considerable arguments about the 'age and stage' issue. The ages suggested for the development of cognitive capacity quoted from the selected sample of children studied by Piaget and his co-workers were found unrealistically low in large scale studies, and showing a great range of variation (e.g. see Shayer et al., 1976).

The issues of décalage, raised by the original researchers themselves, were used to detract from the theory. But the fact of development with age of cognitive ability of individual children, however varied they are in their genetic inheritance and in the richness of their upbringing, remained difficult to disprove or ignore. It remained the basis for neo-Piagetian research (e.g. see Demetriou et al., 1992) and in the case of pedagogy it underpinned the work of the Cognitive Acceleration through Science Education (CASE) projects which demonstrated considerable success in raising levels of achievement in later adolescence attributable to intervention in early adolescence (pupils aged 11-13) planned specifically with the type of cognitive conflicts Piaget suggested as the mechanism for development of higher mental functions (Adey et al., 1994).

Piagetian psychology emphasises individual maturation through direct experiences in handling concepts, and regards language and communications as secondary and derivative. Use of language is seen useful to the individual only if the words and symbols connect with concepts already assimilated and operational within the mental structures. Thus words and symbols makes it possible to anchor and automatise concepts, paving the way for their incorporation in yet higher order thinking. The Piagetian clinical experiments were designed to infer thinking processes primarily from actions and solutions to problems children can be observed accessing directly, rather than by inference indirectly from their communication in prose of their response to texts in, for example, the areas of history or literature. Although Piaget did not address issues of learning and teaching, the message for pedagogy is primarily to attend to the readiness factor, and to the design of cognitive challenges in learning situations appropriate for the individuals.

\section{Vygotsky and social constructivism}

Vygotskian psychology emphasises the fact that the individual interacts with the outside world primarily in social settings, that the experiences of a growing child are largely mediated by adults and by the peer group. These social settings, 
embodied in the language and culture within the immediate surrounds of the learning situation are the main influences that frame the meanings of events and elements of reality in the individual mind. Vygotsky (1985) argued:

“Any function in the child's cultural development appears twice, or on two planes. First it appears on the social plane, and then on the psychological plane. First it appears between people as an interpersonal category, and then within the child as an intra psychological category." [And] "...instruction is good only when it proceeds ahead of development, when it awakens and rouses to life those functions that are in the process of maturing or in the zone of proximal development" ( $p$ 165).

But the application of these ideas to teaching is no easy matter.

In remediating work for adolescents developed over some 15 years Feuerstein (1980) found that it was necessary to develop further Vygotsky's concept of mediation. In effect, while the successful performance 'between people' ('interpersonal category') provides the opportunity for each adolescent to witness, internalise and make their own, as a step in development ('intrapersonal category'), this development will more usually be accomplished as a result of the inputs from one of the child's peers. The teacher is too far away from where the adolescent is to know successfully what to offer, and the adolescent may not easily accept the modelling from this adult even if good. Thus the teacher mediation has to be indirect. That is, the teacher needs to manage the phases of a lesson in such a way that the proportion of opportunities each pupil gets to receive mediation that is, good ideas, often newly-minted and delivered in language and symbolic action which may be only just ahead of where another pupil presently is - from his or her peers is increased by a large factor, perhaps tenfold. The pupils are mediating each other, but the teacher stage-manages the whole process.

Constructivism has come to represent a major philosophical/psychological position in the discourse of mathematics education, from the early 1980's (and the writings of von Glaserfeld) to the $1990 \mathrm{JRME}$ monograph Constructivist Views on the Teaching and Learning of Mathematics. More recently a number of papers have been published in Educational Studies in Mathematics (ESM), with those from two issues in 1994 reprinted in a book edited by Cobb (1994). The book includes a paper by Voigt which is of particular relevance to the present paper. Voigt addresses the importance of 'negotiation' and the notion that the teachinglearning process be coisidered as a social interaction. He takes the construct of 'ambiguity' as an essential characteristic of the teaching-learning situation as this in turn leads to 'negotiation'; we would suggest further that the idea of 'ambiguity' could be made explicit, i.e., invoked through intervention, to become 'cognitive conflict', leading to interaction/negotiation.

Voigt focuses on interaction and the "chance of mediating the foci on the subject and on culture" ( $p$ 187). In subsequent discussion he notes the importance of the pupils' contributions to classroom discourse, the 'mathematical theme', and that pupils' thinking and the mathematical theme develop reflexively - the pupil's 
learning contributes to the evolution of the theme which contributes to the pupil's learning. This in turn raises an additional issue, that is that

"in the mathematics classroom pupil's do not only learn mathematics, they also learn to negotiate mathematical meanings with an expert, the teacher (underline ours)" (p 191).

We would suggest here that this in fact does not go far enough, but rather linking the work of Feuerstein with social constructivism, another important aspect of this negotiation is that of pupil-pupil or pupil(s)-computer interaction/negotiation and collaboration, i.e., pupils learning through negotiation with their peers.

\section{Piaget and Vygotsky in tandem}

Piagetian psychology and Vygotskian psychology (and social constructivism) are often described as conflicting or contrasting. Our position is that we see them in fact complementing each other. At any given moment in time the individual child is capable of carrying out only mental activity that can be reasonably expected according to the Piagetian model of cognitive developmental stages. At the same time the process of learning, i.e., assimilation (of new experiences into one's own mental structures) and accommodation (of the mental structures to significantly novel experiences) is framed by the mediating role of the teacher and the classroom interaction with peers described by Vygotsky and Feuerstein. Vygotsky (1978) speaks of deliberately promoting the 'zone of proximal development':

"We propose that an essential feature of learning is that it creates the zone of proximal development; that is, learning awakens a variety of internal developmental processes that are able to operate only when the child is interacting with people in his environment and in co-operation with his peers. Once these processes are internalised, they become part of the child's independent developmental achievement" (p 90).

The 'internal developmental processes' that are to be awakened belong to the individual, so, effectively, the zone of proximal development implies rather than denies the Piagetian cognitive stages. It supplies the mechanism for the development which Piaget and collaborators describe and Piaget himself acknowledges (Piaget, 1962, 13-14).

\section{CAME THINKING MATHSTM LESSONS}

Initial work of the Cognitive Acceleration in Mathematics Education (CAME) research included a feasibility study with pupils aged 11-13. The focus was on the development and trailing of exemplary lessons with attention given to observing pupils engaged in the lesson tasks. The design and conduct of the lessons embodied an attempt at a synthesis of Piagetian psychology, with its emphasis on appropriate cognitive challenges and the critical importance of 
relating pupils performance of this age range to a model of the level of thinking required by the task as related to the present level of thinking of the pupil; and Vygotskian psychology and social constructivism, with their emphasis on social interactions and the role of language. The synthesis also took into account the considerable research in mathematics education, especially on difficulties experienced by pupils in the learning of key topics (e.g., see Johnson, 1989).

The integrative approach to Piagetian and Vygotskian psychology's was reflected in a number of features identifiable in the CAME lessons. The class needs first to be challenged to define and agree amongst themselves the nature of the task in front of them (concrete preparation). The task itself needs to be structured according to psychological principles and also to be true to the school subject matter in which it is contextualised (mathematical formalisation). Each intervention lesson has an individual or small-group session of work on task where pupils know the essential thing is to test the ideas and strategies they are using (construction and cognitive conflict) and share their ideas with their peers (the Vygotskian/social constructivism perspective). This is because they know they will be invariably be asked to contribute, after work-on-task, to a whole-class discussion when, as far as possible, everything of note which has occurred anywhere in class is shared (further construction). Finally, as a last short episode when new powers are active in their minds the pupils are asked to find good descriptive names (words or phrases) for the new ideas which they can share (metacognition), and to recall or invent other contexts for their use (bridging). The nature of these lessons can be considered to be analogous to 'teaching an investigation' (or 'teaching for the solution of a problem'), as contrasted with the usual situation of 'letting the pupils get on with it'. However, as indicated above, the main aim is to increase intellectual development and to 'move' pupils towards/into formal reasoning (Piagetian age-stage).

\section{Computing environments - the 'added ingredient'}

Attention is drawn here to three other chapters in this book which provide computing environment exemplars of aspects of the CAME approach:

- Leron: 'applied constructivism; successive refinement in the approach to a computer based problem task';

- Hoyles: 'proving, including pupils contrasting and comparing approaches',

- Sutherland: 'computer feedback and teacher mediation'.

While these authors may not be explicit in their attention to the full range of constructs described above, the notions of, for example, cognitive conflict, construction and metacognition are themselves embedded in the social interactions described, both pupil-pupil and pupil(s)-machine (Leron, Hoyles), and in the importance ascribed to teacher intervention/mediation (Sutherland).

The theoretical foundation proposed in CAME both draws upon work presented in earlier IFIP conferences and extends this to include new constructs. 
Adhami, Johnson \& Shayer: Cognitive development and classroom interaction 211

This in turn provides further insights and explanations for the efficacy of powerful computing environments.

\section{TEACHERS' ADOPTION OF THE APPROACH}

The CAME approach places two major demands on the experience and expertise of teachers. The first of these is linked to the Piagetian aspect. Here the teachers' knowledge of the strengths and weaknesses of their pupils along with an awareness of (cognitive) developmental levels - the experiential and theoretical perspectives - is paramount as this provides the basis for the matching of classroom activities to the processing capabilities of pupils.

The second component in the approach is that of teacher intervention or mediation to promote pupil-pupil interaction and pupils mediating each other. The demand here in terms of expertise in the classroom management skills required to facilitate the approach has been found to be particularly acute in the early stages of implementation. Professional development in this area takes time. However, this development has also been found to be considerably enhanced through the application of aspects of the same theory which underpins pupil activity in a TM lesson - teachers interacting with other teachers in the sharing of well defined, explicit, experiences.

We contend the approach cannot be readily assimilated from written materials and guidance. At least three critical steps are identified for this approach to be adopted by teachers. Firstly teachers need to be convinced there is a problem of under-achievement at the higher school. Teachers need to be convinced that this under-achievement is primarily due to inadequate challenge in the lower school. They need to be convinced of the crucial importance of early adolescence growth spurt, whether as biological fact with cognitive implications, or at least as an empirical conclusion allied to the potential of benefiting from teaching if problems are addressed early.

Secondly the teachers need to recognise the subtle difference between the agenda of the Thinking Maths lessons and the normal agenda for good teaching in the same topic. Instead, say, of planning a lesson around one major learning point hopefully to be achieved by all, the teacher has to look at the underlying agenda in a developmental way, in which there may be, for the same agenda, many different levels of realisation of achievement, each one of which is valid for particular pupils. We have found that the difficulty here can be addressed cumulatively over time, with frequent (time-tabled) discussions amongst colleagues focused on specific lessons observed. There are two aspects to this step relevant to the interactions amongst colleagues: one is that the same lesson may well need to be adjusted to suit specific classes according to their abilities, the other is that classroom interactions are dependent on a teacher's own style. Hence there is more to teachers' discussions about lessons than matching experience with written agenda and specimen interactions. They need to disentangle the 
invariant features of successful cognitive intervention in a given lesson from its surface features that are variable for different classes and different teachers.

Thirdly, teachers, having made the distinction of the agenda, and having gained ownership of lessons in terms of adapting them to their own classes and styles, will approach the rest of the maths curriculum with a fresh perspective. Strands of fruitful thinking and activity that have been identified, but not followed up in TM lessons, are developed later, i.e., the topic approached with an emphasis on thinking rather than on procedures and notation, more time given to focused classroom talk and pupils listening to each other, and to addressing misconceptions.

There is a parallel between the mode of work of a pupil in a TM lesson and a teacher's own professional development. Both start from an activity with much structured help and preparation, both then make sense of it through dealing with cognitive challenges, and both end by reflecting on their methods and concepts, attempting to use them in other situations. The end-product is the implementation of an approach embodying theory-based teaching with the goal being that of enhanced learning - pupils operating at a level consistent with their own realisable cognitive potential.

\section{REFERENCES}

Adey, P., and Shayer, M. (1994). Really Raising Standards. London: Routledge.

Cobb, P. (ed.) (1994) Learning Mathematics: Constructivist and Interactionist Theories of Mathematical Development. Dordrecht, The Netherlands: Kluwer Academic Publishers. [A collection of papers reprinted from Educational Studies in Mathematics, 26 (2-3).]

De Corte, E. (1993). Psychological aspects of changes in learning supported by informatics. In D. Johnson and B. Samways (eds.) Informatics and Changes in Learning. Amsterdam: IFIP, Elsevier Science (North-Holland), 37-47.

Demetriou, A., Shayer, M. and Efklides A. (eds.) (1992). Neo-Piagetian theories of cognitive development. London: Routledge.

Feuerstein, R., Rand, Y., Hoffman, M., and Miller, M. (1980). Instrumental Enrichment: an intervention programme for cognitive modifiability. Baltimore: University Park Press.

Jensen, J. and Nissen, T. (1987). Learning and learnability: a frame of reference for pedagogic argumentation. In $\mathrm{D}$. Johnson and $\mathrm{F}$. Lovis (eds.) Informatics and the Teaching of Mathematics. Amsterdam: IFIP, Elsevier Science (NorthHolland), 67-73.

Johnson, D.C. (ed.) (1989). Children's Mathematical Frameworks 8-13: A study of Classroom Teaching. Windsor: NFER-NELSON (Re-printed, Nottingham University: Shell Centre for Mathematical Education). 
Kilpatrick, J. (1978). Theories of learning and their implications for teaching informatics and mathematics. In D. Johnson and D. Tinsley (eds.) Mathematics and Informatics in Secondary Schools. Amsterdam: IFIP, NorthHolland, 93-100.

Piaget, J. (1962). Comments on Vygotsky's critical remarks concerning The Language and Thought of the Child and Judgement and Reasoning in the Child. Boston: MIT Press.

Shayer, M., Küchemann, D. and Wylam, H. (1976). The distribution of Piagetian stages of thinking in British middle and secondary school children. British Journal of Educational Psychology, 46, 164-173.

Vygotsky, L.S. (1978). Mind and Society. Cambridge, Mass.: Harvard University Press.

Vygotsky, quoted in J. Wertsch (ed.) (1985). Culture, Communication and Cognition: Vygotskian perspectives. Cambridge: Cambridge University Press.

Mundher Adhami is a Research Fellow in Mathematics Education at King's College London. He works in the CAME project, investigating issues involved in the professional development of teachers in relation to pedagogic innovationwith special consideration given to the teaching approach of cognitive stimulation employed in special lessons for 11-13 year olds. His experience includes computer modelling, being Head of mathematics and computing in London comprehensive schools, curriculum development in the Graded Assessment in Mathematics (GAIM) project, government school inspections, and serving as an examination subject officer at the University of London Examination and Assessment Council.

David Johnson took up the post of Shell Professor of Mathematics Education in the University of London in 1978, following 17 years at the University of Minnesota (US). His teaching experience and research activity spans all levels from primary through university and he has been involved in school computing since 1963; activities which utilised hardware starting with mainframes in the early days, through time-share and leading on to today's micros and powerful new technologies, software and supporting equipment. He has been a member of WG3.1 (and contributor to the working group publications) since its early days.

Michael Shayer is Professor of Applied Psychology, School of Education, King's College London. In the 1970 s he was responsible for conducting a massive survey (14,000 children between 10 and 16 years of age) in Britain, using three Piagetian tests, which showed that only $30 \%$ of the population achieved even early formal operations by the age of 16 . After replicating the intervention work of Reuven Feuerstein, he initiated the context-delivered style of intervention in the CASE (Cognitive Acceleration through Science Education) projects in the $80 \mathrm{~s}$. He is a member of the CAME team working to do the same within mathematics. 